\title{
Decreased arylesterase activity and increased total oxidative status in rosacea
}

\section{Sertac Sener', Fadime Kilinc', Ayse Akbas', Ahmet Metin², Suzan Demir Pektas ${ }^{3}$, Salim Neselioglu ${ }^{4}$, Ozcan Erel ${ }^{4}$}

${ }^{1}$ Dermatology Clinic, Ataturk Training and Research Hospital, Ankara, Turkey, ${ }^{2}$ Department of Dermatology, Yildirim Beyazit University Medical Faculty, Ankara, Turkey, ${ }^{3}$ Department of Dermatology, Aydin State Hospital, Aydin, Turkey, ${ }^{4}$ Department of Biochemistry, Yildirim Beyazit University Medical Faculty, Ankara, Turkey

Corresponding author: Sertac Sener, MD, E-mail: sertacsnr@yahoo.com

\begin{abstract}
Background: Rosacea is an inflammatory skin disease of face. In recent years, it is revealed that imbalance is significant in oxidant/antioxidant system in pathophysiology. Objective: In this study, the role of oxidative stress on rosacea was investigated. Methods: 34 rosacea patients and 33 healthy control cases between 18 and 70 years old are included in the study. In all the cases, serum lipids, Paraoxonasel (PONl), stimulated Paraoxonasel (stPONl), Arylesterase(ARES), Total Oxidant Status (TOS) and Total Antioxidant Status (TAS) levels are measured. Results: ARES levels were significantly lower and TOS levels were significantly higher in the patient group (p<0,001). Oxidative Stress Index (OSI) was found to be shifted towards the oxidative side in the patient group $(\mathrm{p}<0,001)$. Conclusion: This situation shows that oxidative stress may have a role in the rosacea pathophysiology.
\end{abstract}

Key word: Arylesterase; Rosacea, Oxidative stress; Total antioxidant capacity; Total oxidant status

\section{INTRODUCTION}

Rosacea is a chronic, inflammatory disease with exacerbations. The disease affecting the capillary vessels and pilosebaceous unit, is characterized by midfascial erythema, telangiectasia, papules and pustules [1]. It is known four subtypes [2] as erythematotelangiectatic (type I), papulopustular (II), phimatous (III) and ocular rosacea (IV). Pathophysiological mechanism is associated with inflammation triggered with ultraviolet (uv) radiation, vascular changes, microorganisms or oxidative tissue damage [3]. Researches have revealed that imbalance in oxidant/antioxidant system is an important factor in rosacea. In rosacea patients, high serum peroxide level and low tissue superoxide dismutase (SOD) activity were shown [4,5]. Skin biopsy samples were taken from the rosacea patients and the healthy controls. Reactive oxygen species (ROS) and SOD levels were determined. In rosacea lesions, there was a higher ROS activity and a lower SOD level when compared to the controls [6]. The inhibition of ROS activity in neutrophils with various topical and systemic drugs used in the treatment of rosacea supports the "oxidative stress phenomenon" hypothesis [7-9]. On the other hand, PONl is an enzyme having antioxidant and anti-inflammatory activity and it was found that serum PONl levels decreased in rosacea [10].

In the studies performed till now, generally oxidant and antioxidant molecules were measured separately. In this study, we evaluated TOS and TAS and investigated whether oxidative stress had a role in rosacea or not.

\section{MATERIAL AND METHOD}

The planned prospective controlled study was accepted by the ethics committee of our hospital. All the cases had signed the informed consent form and their approvals were taken.

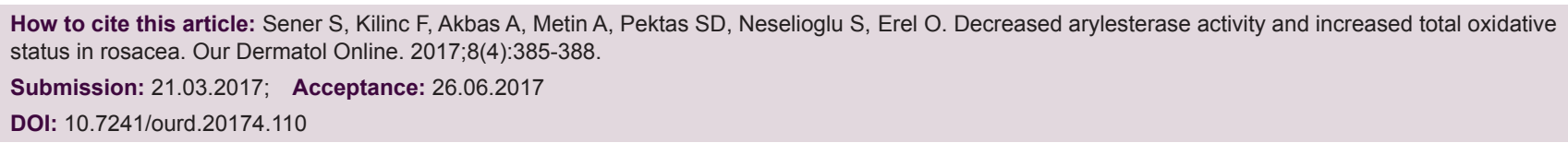


Thirtyfour rosacea patients and 33 healthy controls were included in the study. None of the cases was using any drugs, alcohol or tobacco and they had no additional diseases. The patients were divided in subtypes by using The National Rosacea Society classification [2]. Nine patients was evaluated as subtype I, 16 patients as subtype II and 9 patients as subtype III. In addition to the skin lesions, 7 patients having eye involvement were also noted.

The serum PON, stPON, ARES, TAS, TOS, triglyceride (TG), total cholesterol (TC), low-density lipoprotein (LDL), high-density lipoprotein (HDL) levels were measured and OSI was calculated in all cases. TOS and TAS levels were determined by using new automatic colorimetric measurement methods $[11,12]$. TOS results were calibrated and expressed as micrometer hydrogen peroxide equivalent per liter $\left(\mu \mathrm{MH}_{2} \mathrm{O}_{2} \mathrm{Eq} / \mathrm{L}\right)$. TAS results were shown as (mmolTroloxEq/L). OSI (arbitrary unit) was calculated according to the TOS/TAS X 100 formula. PON and ARES activities were measured by using commercial kits and the results were recorded as $\mathrm{kU} / \mathrm{L}$.

\section{RESULTS}

Thirty four rosacea patients (13 males) with an average age of 47,41 $\pm 8,84$ and 33 healthy cases (16 males) with an average age of 47,76 $\pm 10,57$ were included in the study. There was no significant difference between the groups in terms of age and gender $(\mathrm{p}>0.05)$.

ARES levels were significantly lower and TOS levels were significantly higher in the patient group $(p<0,001)$. OSI was found to be shifted towards the oxidative side in the patient group $(\mathrm{p}<0,001)$. The results are shown in the Table 1 .

Also serum TG levels were significantly higher in the patient group $(Z=2.051, p<0,05)$. The serum $P O N$, stPON, TAS, TC, LDL and HDL levels did not show a statistically significant difference between the groups $(\mathrm{p}>0,05)$.

A positive correlation was found between TAS and TG levels in the patient and control groups $(\mathrm{r}=0.647$ and $\mathrm{r}=0.667$, respectively; $\mathrm{p}<0.001)$. No significant relation was found between oxidative stress (TAS, TOS, OSI) levels and age, rosacea subtype, disease duration or eye involvement.
Table 1: Laboratory findings of the rosacea patients and the healthy controls

\begin{tabular}{lcccc}
\hline Measurement & Patients & Controls & $\begin{array}{c}\text { Statistics } \\
\text { test }\end{array}$ & $\mathbf{P}$ \\
\hline TG & $117.00(69.25)^{1}$ & $96.00(54.00)$ & $\mathrm{Z}=2.051$ & $0.040^{*}$ \\
TC & $208.74 \pm 43.22^{2}$ & $192.09 \pm 39.27$ & $\mathrm{t}=1.648$ & 0.104 \\
HDL & $47.14 \pm 9.90$ & $48.52 \pm 11.96$ & $\mathrm{t}=-0.517$ & 0.607 \\
LDL & $129.17 \pm 27.54$ & $121.66 \pm 31.93$ & $\mathrm{t}=1.032$ & 0.306 \\
PON1 & $176.00(234.00)$ & $213.00(130.00)$ & $\mathrm{Z}=1.079$ & 0.281 \\
ARES & $195.00(66.00)$ & $292.00(22.50)$ & $\mathrm{Z}=6.842$ & $0.001^{*}$ \\
STPON1 & $378.50(436.50)$ & $345.00(241.00)$ & $\mathrm{Z}=0.414$ & 0.679 \\
TAS & $2.15(0.42)$ & $2.21(0.27)$ & $\mathrm{Z}=1.198$ & 0.231 \\
TOS & $10.80 \pm 2.64$ & $8.79 \pm 1.89$ & $\mathrm{t}=3.570$ & $0.001^{*}$ \\
OSI & $0.05 \pm 0.01$ & $0.04 \pm 0.01$ & $\mathrm{t}=3.518$ & $0.001^{*}$ \\
\hline
\end{tabular}

${ }^{1}$ median (IQR); ${ }^{2}$ mean \pm Sd, TC: Total cholesterol, TG: triglycerid,

HDL: high density lipoprotein, LDL: low density lipoprotein,

PON: paroxonase, STPON: stimulated PON, ARES: arylesterase,

TOS: total oxidant status, TAS: total antioxydant status, OSI: oxydative stress index. The normally distrubuted variables are reported as mean \pm standard deviation (mean \pm sd) and compared with independent samples t-test and non-normally distrubuted variables are reported as interquartile-ranges (IQR) (median) and compared with Mann-Whitney $U$ test *statistically significant

\section{DISCUSSION}

In this study, we have evaluated the effect of oxidative stress in rosacea patients. Independent from the rosacea subtypes, TOS levels were increased in the patients' group. ARES activity was lower and triglyceride (TG) levels were significantly higher in the patients' group as well.

Vascular and inflammatory factors play role in the pathophysiology of rosacea $[3,13]$. Inflammation is related to the oxidative processes of proteins and lipids. ROS damages the activation of natural defense system, changes the lipid balance and stimulates the inflammatory mediators such as cytokines [14]. Activated inflammatory cells, especially neutrophils, provide ROS release in rosacea. On the other hand, uv radiation cause ROS production on the skin and it is an important factor aggravating rosacea. As a result, these free oxygen radicals cause oxidation of lipids and lipoproteins [15-18].

The study of Baz et al. have showed that rozacea is an oxidative stress situation. They found increased ROS activity and decreased antioxidant potential due to high malondialdehyde levels [19].

PONl is an antioxidant and anti-inflammatory enzyme associated with HDL and it has PON, ARES and dyazoxonase activities. This enzyme prevents the oxidation of serum lipoproteins and the accumulation of hydrolyzed lipid peroxide. The oxidative medium caused by the free radicals and peroxides oxidizes 
the sulfhydryl groups of PON and ARES enzymes, and PONl enzyme activity decreases [20,21]. In other words, when the medium is oxidated more, PON and ARES enzyme activities decrease leading to a diminished antioxidant capacity. Various studies showed decreased PONl activity in systemic diseases including metabolic syndrome, atherosclerosis, diabetes mellitus and in various skin diseases such as psoriasis, recurrent aphtous stomatitis [22-25]. Takc1 et al. reported that PONl activity (PON and ARES) is lower and serum lipid hydroxyperoxide levels are higher in rosacea patients indicating increased oxidative stress in rosacea [10].

Up to now, different oxidant and antioxidant molecules in rosacea has been investigated. However separate measurements of these molecules require complex and expensive methods. Also they may cause false results due to the additive effect. Our TOS measurement method shows the global effect of numerous oxidants and also our TAS measurements reflect the total effect of various antioxidants in the organism. These methods are rapid, cheap, easy and reliable. It has also been shown by this method that oxidative stress was increased in vitiligo, aphtous stomatitis, psoriasis and seborrheic dermatitis [22,26-28].

Although TAS level is not statistically different from the control group, this study suggests inflammation-related TOS level increases and ARES activity decreases in rosacea. Besides, OSI which is the essential indicator of oxidative stress shifts towards the oxidative stress side. In fact human body is a dynamic system. Despite the attacks of free radicals, every metabolic process in the organism is in relation with other processes in order to maintain the oxidant/antioxidant balance [18]. In our study, the increase in oxidation observed in rosacea patients possibly decreased the antioxidant ARES enzyme activity. However no significant decrease occurred in the PONl levels and TAS.

\section{CONCLUSION}

This study suggests that oxidative stress contributes to the rosacea pathophysiology. TOS and TAS levels measurement is a reliable method to determine oxidative stress in rosacea.

\section{REFERENCES}

1. Crawford GH, Pelle MT, James WD. Rosacea: I. Etiology, pathogenesis, and subtype classification of rosacea. J Am Acad
Dermatol. 2004;51:327-41.

2. Wilkin J, Dahl M, Detmar M, Drake L, Liang MH, Odom R, et al. Standard grading system for rosacea: report of the National Rosacea Society Expert Committee on the classification and staging of rosacea. J Am Acad Dermatol. 2004;50:907-12.

3. Yamasaki K, Gallo RL. The molecular pathology of rosacea. J Dermatol Sci. 2009;55:77-81.

4. Briganti S, Picardo M. Antioxidant activity,lipid peroxidation and skin diseases. What's new? J Eur Acad Dermatol Venereol. 2003;17:663-9.

5. Tisma VS, Basta-Juzbasic A, Jaganjac M, Brcic L, Dobric I, Lipozencic J, et al. Oxidative stress and ferritin expression in the skin of patients with rosacea. J Am Acad Dermatol. 2009;60:270-6.

6. Oztas MO, Balk M, Ogus E, Bozkurt M, Ogus H, Ozer N. The role of free oxygen radicals in the aetiopathogenesis of rosacea. Clin Exp Dermatol. 2003;28:188-92.

7. Bakar O, Demirçay Z, Yuksel M, Halar G, Sanisoglu Y. The effect of azithromycin on reactive oxygen species in rosacea. Clin Exp Dermatol. 2007,32:197-200.

8. Miyachi Y, Yoshioka A, Imamura S, Niwa Y. Effect of antibiotics on the generation of reactive oxygen species. J Invest Dermatol. 1986;86:449-53.

9. Miyachi Y, Imamura S, Niwa Y. Anti-oxidant action of metronidazole: a possible mechanism of action in rosacea. Br J Dermatol. 1986;114:231-4.

10. Takc1 Z, Bilgili SG, Karadağ AS, Kucukoğlu ME, Selek S, Arslan M. Decreased serum paraoxonase and arylesterase activities in patients with rosacea. J Eur Acad Dermatol Venereol. 2015;29:367-70.

11. Erel O. A new automated colorimetric method for measuring total oxidant status. Clin Biochem. 2005;38:1103-11.

12. Erel O. A novel automated direct measurement method for total antioxidant capasity using a new generation, more stable ABTS radical cation. Clin Biochem. 2004;37:277-85.

13. Gomaa AH, Yaar M, Eyada MM, Bhawan J. Lymphangiogenesis and angiogenesis in non-phymatous rosacea. J Cutan Pathol. 2007;34:748-53.

14. Jones D. Reactive oxygen species and rosacea. Cutis. 2004;74:32-4.

15. Jones DA. Rosacea, reactive oxygen species, and azelaic acid. J Clin Aesthet Dermatol. 2009;2:26-30.

16. Cornobare MD. Skin photosensitizing agents and the role of reactive oxygen species in photoaging. J Photochem Photobiol. 1992;14:105-24.

17. Naru E, Suzuki T, Moriyama M, Inomata K, Hayashi A, Arakane K, et al. Functional changes induced by chronic UV A irradiation to cultured human dermal fibroblast. Br J Dermatol. 2005;153(Suppl 2):6-12.

18. Kohen R, Nyska A. Oxidation of biological systems: oxidative stress phenomena, antioxidants, redox reactions, and methods for their quantification. Toxicol Pathol. 2002;30:620-50.

19. Baz K, Cimen MYB, Kokturk A, Aslan G, Ikizoglu G, Demirseren DD, et al. Plasma reactive oxygen species activity and antioxidant potential levels in rosacea patients: correlation with seropositivity to Helicobacter pylori. Int J Dermatol. 2004;43:494-7.

20. Canales A, Sanchez-Muniz FJ. Paraoxonase something more than an enzyme? Med Clin (Barc). 2003;121:537-48.

21. Watson AD, BerlinerJA, Hama SY, La Du BN, Faull KF, Fogelman AM, et al. Protective effect of high density lipoprotein associated paraoxonase. Inhibition of the biological activity of minimally oxidized low density lipoprotein. J Clin Invest. 1995;96:2881-91.

22. Akoglu G, Metin A, Kilinc F, Pektas SD, Isikoğlu S, Akbas A, et al. Total serum oxidant/antioxidant status and arylesterase activity in recurrent aphthous stomatitis. Ann Dermatol. 2013;25:273-7.

23. Senti M, Tomas M, Fito M, Weinbrenner T, Covas MI, Sala J, et al. Antioxidant paraoxonase 1 activity in the metabolic syndrome. J Clin Endocrinol Metab. 2003;88:5422-6.

24. Boemi M, Leviev I, Sirolla C, Pieri C, Marra M, James RW. Serum paraoxonased reduced in type 1 diabetic patients compared ton 


\section{www.odermatol.com}

on-diabetic, first degree relives; influence on the ability of HDL to protect LDL from oxidation. Atherosclerosis. 2001;155:229-35.

25. Ferretti G, Bacchetti T, Campanati A, Simonetti O, Liberati G, Offidani A. Correlation between lipoprotein(a) and lipid peroxidation in psoriasis: role of the enzyme paraoxonase-1. Br J Dermatol. 2012;166:204-7.

26. Emre S, Metin A, Demirseren DD, Akoglu G, Oztekin A, Neselioglu S, et al. The association of oxidative stress and disease activity in seborreic dermatitis. Arch Dermatol Res. 2012;304:683-7.

27. Akoglu G, Emre S, Metin A, Akbas A, Yorulmaz A, Isikoglu S, et al. Evaluation of total oxidant and antioxidant status in localized and generalized vitiligo. Clin Exp Dermatol. 2013;38:701-6.

28. Emre S, Metin A, Demirseren DD, Kılıç S, Isikoglu, Erel O. The relationship between oxidative stress, smoking and clinical severty of psoriasis. J Eur Acad Dermatol Venereol. 2013;27:e370-5.

Copyright by Sertac Sener, et al. This is an open-access article distributed under the terms of the Creative Commons Attribution License, which permits unrestricted use, distribution, and reproduction in any medium, provided the original author and source are credited.

Source of Support: Nil, Conflict of Interest: None declared. 